\title{
Las tensiones del yo escritor: el diario como lugar de experimentación en José Donoso y Ágata Gligo.
}

\section{Resumen}

Con la publicación de Correr el tupido velo (2009) se puede acceder a fragmentos del diario de escritor de José Donoso, por su parte, Diario de una pasajera (1997) es el registro de los últimos años de vida de Ágata Gligo. Estos textos autobiográficos son entendidos por los mismos autores como parte de su obra. Y a pesar de que hay en ellos una intimidad que se sabe saldrá a la luz, se evidencia una necesidad por llevar a cabo su escritura. En el caso de Gligo, ella recibe el mandato del mismo Donoso de llevar un diario para hacer frente a su sequia narrativa y la cercanía de la muerte. Por su parte, el novelista es sumamente prolífico en la escritura de estos, consolidándolos como el lugar para el desahogo de sus temores e inseguridades. Alberto Giordano (2009) propone que escribir sobre sí mismos les da a los sujetos la posibilidad de conocerse y desconocerse, en síntesis, crear su propia figura, lo que permite el despliegue de toda la capacidad narrativa de sus autores llevándolos hacia la hibridación del género, en el que además se da espacio para la reflexión metatextual sobre su propia obra y la de sus contemporáneos, constituyendo el gesto doble de crítica y posicionamiento/construcción de un campo cultural, dentro de la escritura diarística.

Palabras claves Autobiografía, Diario de escritor, José Donoso, Ágata Gligo.

\begin{abstract}
With the publication of Correr el tupido velo (2009,) we can access to fragments of Jose Donoso's diary; on the other hand, Diario de una pasajera (1997) is the record of Agata Gligo's last days of life. This autobiographic texts are understood by their authors as parts of their work. Although there's a deeper intimacy that is knows that will come to light, there is evidence of a necessity to get through their writing. In the case of Gligo, she recibes the order from Donoso himself to start a diary to face her narrative dryness and her upcoming death. In the case of Donoso, he is quite prolific in this kind of writing, consolidating as a place of relief his fears and insecurities. Alberto Giordano (2009) proposes that writing about themselves give's the subjects chance to know themselves and again to become unknown, in
\end{abstract}


CATEDRAL TOMADA: Revista de crítica literaria latinoamericana / Journal of Latin American Literary Criticism Las tensiones del yo escritor: el diario c omo lugar de experimentación en José Donoso y Ágata Gligo.

synthesis, to create their own figure, what allows them to display their narrative abilities to the fullest, taking them to the hibridation of the genre, in which it also gives space for metatextual reflection about their contemporaries and their own's work, building the double gesture of critic and building a stance in a cultural field, always inside the writing of their diaries.

Keywords Autobiography, Writer's diary, José Donoso, Ágata Gligo.

"Todo aquí debe ser considerado como dicho por un personaje de novela", advierte Roland Barthes en las primeras páginas de su autobiografía, con este texto el escritor y crítico francés tensiona la concepción de verdad que acompañaba al género autobiográfico hasta ese momento; experimentando, jugando, en definitiva, ficcionalizando su propia vida.

En el caso de los escritores chilenos José Donoso y Ágata Gligo en Correr el tupido velo (2009) y Diario de una pasajera (1997), respectivamente, actualizan el relato autobiográfico desde el formato de diario de escritor, con lo cual la revelación de la intimidad cotidiana de ambos está siempre cruzada con la reflexión sobre su propia obra, tanto la ya escrita, como la que se está escribiendo -en forma paralela al diario-, y la que se escribirá en el futuro, constituyéndose como textos que permiten acceder a la reflexión metatextual detrás de la creación narrativa de estos autores.

En cuanto a Correr el tupido velo, su autoría recae en la hija de Donoso, quien tuvo acceso a los diarios y cuadernos, que su padre vendió a las universidades de Iowa y Princeton con el fin de que sirvieran para el estudio de su obra literaria; estos son incluidos, citándoselos por medio de fragmentos que la autora va hilando junto a su propio relato y contrastándolos con los diarios de su madre. Para la reflexión que aquí voy a plantear me centraré solo en los fragmentos escritos por el propio José Donoso, lo que sin duda constituye una dificultad para el análisis, ya que el crítico debe recomponer una unidad perdida, la que puede superarse debido a que Pilar incluye trozos extensos escritos por su padre y las partes elididas son relatadas en forma de resumen de aquello que no 
puede incorporar. Parece interesante además adentrarse en los pensamientos íntimos del novelista y así establecer un dialogo con el diario de su discípula Ágata Gligo, quien dispuso de la publicación de su propio texto, el que registra los últimos años de su vida (1992-1994).

La escritura del diario de Gligo comienza luego de ser diagnosticada de cáncer mamario y por consejo del mismo Pepe Donoso, cómo se relata en una de las entradas del texto, esto con el fin de hacer frente a su sequia narrativa y la cercanía de la muerte que supone la enfermedad. No se establece un circuito de lectura entre ambos diarios, sin embargo, el hecho de que Donoso como maestro designe aquella tarea para su alumna, hace que su figura se cuele dentro de este de forma admirativa y como una suerte de espejo, relación que abordaré más adelante.

\section{Entre lo público y lo privado: la creación del yo}

En su ensayo El escritor de diarios... (1998) Andrés Trapiello propone a esta forma de escritura del yo como un ideal de la modernidad, que "ama los diarios, y necesita de ellos para una más satisfactoria reconstrucción del presente que huye" (30). Los relatos biográficos y autobiográficos de escritores, despiertan un renovado interés entre sus pares durante la modernidad tardía, así también, la inclusión en el cine de historias de artistas, develan un interés del público por la intimidad de estas personalidades.

En el caso del diario, este constituye un relato autobiográfico del presente, por lo que atenta contra una de las condiciones del género propuesta por Lejeune: la de ser un relato retrospectivo. En los diarios se efectúa una narración del día a día, por lo que no hay mayor distancia entre lo vivido y el proceso de escritura, a diferencia de lo que ocurre en las autobiografías clásicas. Aquí el tiempo es el mismo, lo que impide una distancia reflexiva sobre los hechos que se viven, 
CATEDRAL TOMADA: Revista de crítica literaria latinoamericana / Journal of Latin American Literary Criticism Las tensiones del yo escritor: el diario c omo lugar de experimentación en José Donoso y Ágata Gligo.

construyéndose como una escritura 'en fresco', en la que se plasman los sentimientos e impresiones de forma automática. Respecto a las demás condiciones autobiográficas, vale la pena decir, que el tema tratado en estos diarios, no es solo la propia vida individual, sino que también su vida pública como escritores, la recepción de los lectores y el campo cultural, y la lectura de otros textos contemporáneos. Estos escritos se constituyen entonces como un espacio de crítica -en forma de diario de lectura- y de continua revisión de su propia obra, así sus autores, se identifican como una personalidad reconocible: como escritores de ficciones y hablan desde su nombre propio.

Trapiello también plantea que se escribe un diario cuando el individuo "ha alcanzado el derecho a poder hablar de sí mismo en público, [paradojalmente en ese momento] se retira para poder hacerlo en privado. Aunque lo cierto es que las cosas no volverán nunca a ser las mismas para él, pues desde entonces las fronteras entre lo público, lo privado y lo íntimo parecerán borradas para siempre" (26). Se constituye entonces la escritura diarística, como el lugar de desahogo del sujeto público, lo que puede vincularse a que según Foucault, esta nace por una necesidad del sujeto de cuidarse a sí mismo, concibiéndola entonces como una técnica para el cuidado personal (Giordano, 58).

Estos textos autobiográficos son entendidos por los mismos escritores como parte de su obra, por lo tanto susceptibles de publicación, como bien advierte Alain Girard (Le journal intime 1963), hay en ellos, una intimidad que se sabe saldrá a la luz. Surge entonces la pregunta ¿Por qué escribir un diario? Alberto Giordano (2009), por su parte, propone que escribir sobre sí mismos, les da a estos autores la posibilidad de conocerse y desconocerse, en síntesis, crear su propia figura.

Las estrategias discursivas utilizadas en estos textos apuntan a un desplazamiento del yo: produciéndose la no coincidencia del sujeto consigo mismo, es decir, la disociación entre el sujeto de la enunciación y el sujeto del enunciado. En El espacio biográfico, Leonor Arfuch pone como una de las bases de sus postulados el dialogismo de todo discurso apuntado por Bajtin, "Para 
Bajtin no hay coincidencia entre autor y personaje ni siquiera en la autobiografia" (Arfuch 13). El autobiógrafo es entendido como un "Sujeto que se expresaría a través del discurso a otro que se constituye a través de aquél” (13). El sujeto debe ser pensado entonces a partir de su otredad.

El autor -el novelista- construye un personaje de sí mismo, entregándose por completo a su oficio. La necesidad por narrar ficciones se cuela incesantemente en la escritura de las experiencias íntimas, impidiendo que el autor se entregue por completo a la verdad que supondría el género autobiográfico.

Este deseo por delinear su propio personaje se debe a las problemáticas que atormentan a estos sujetos. En el caso de Ágata Gligo su enfermedad y cierto desprecio por parte del medio cultural y en Donoso se evidencia una obsesión por ocultar su identidad sexual, la que cree que saldrá a la luz, además de las inseguridades respecto a su propia labor como escritor. El fluir de la escritura del diario le permite así a estas subjetividades un desahogo, un espacio alternativo de escritura sobre sí mismos, donde se tematizan sus vidas y que sirve para completar una verdad intima, a la vez que es escrita para ser conocida. Los autores delinean su propia máscara como figuras públicas, develando su intimidad y sus inseguridades de la forma en que ellos quieren que sean conocidas.

En su libro Autobiografía como autofiguración, José Amícola propone una equiparación entre la imagen pública y la imagen que el individuo tiene para sí, como mecanismo dentro de los relatos autobiográficos. Este recurso es designado como autofiguración, lo que al momento de recepción de la obra se traduce en cierta desconfianza, siendo el lector capaz de captar estas tensiones. Así las estrategias de autorepresentación ponen en duda el pacto autobiográfico entre lector y autor propuesto por Lejeune. 
CATEDRAL Tomada: Revista de crítica literaria latinoamericana / Journal of Latin American Literary Criticism Las tensiones del yo escritor: el diario c omo lugar de experimentación en José Donoso y Ágata Gligo.

\section{Ficción y realidad en la escritura diarística}

Estos recursos además de tener un efecto sobre el lector, intervienen en el mundo narrado alejándolo de la "realidad", en la medida en que tienden a imponer un orden inexistente. Esto no se produce en los diarios por el efecto de la memoria como agente distorsionador del relato, como ocurre en la autobiografía clásica, sino que, por la condición de escritor profesional de su autor, quien no renuncia nunca a intervenir la realidad. Los diarios de escritor se configuran entonces como textos confesionales, ficcionales y como espacio de reflexión creadora de los autores.

Al decir que son ficcionales, quiero decir, que están sometidos a una creación artística consiente, con lo que doy un salto desde la autobiografía, al género de la autoficción. Respecto a este vínculo, Enrique Vila Matas, plantea que "la autoficción es la autobiografia bajo sospecha" (Bradu 75). En la autoficción, hay una incertidumbre permanente respecto a si su autor real y protagonista-narrador coinciden. Este género constituye el gesto negativo del escritor, quien no quiere reconocerse plenamente en lo narrado, a diferencia de lo que ocurre en los diarios, que realizan el gesto positivo de afirmación de la identidad real con el Yo interno del relato. Para Fabienne Bradu (2009) la opción por la autoficción se debe a cierta timidez o vergüenza por parte de los autores, sobre lo cual Manuel Alberca se pregunta si

¿Podría ser la autoficción el reconocimiento explícito de que cuando se narra la vida propia es imposible no hacer "ficción" e imposible no mezclar lo recordado con lo inventado, lo soñado con lo deseado y esto con lo real? Podría ser. Pero también podría estar señalando un elaborado subterfugio para esconder pudorosamente lo que no se quiere exponer al juicio público, cuando no una estratagema para agredir o difamar a los otros desde la impunidad. (Bradu 75) 
Mucho antes Cortázar responde a esta pregunta en Diario para un cuento (Deshoras 1964), donde se posiciona en un espacio intermedio entre ficción y realidad, llevando al lector entre uno y otro polo, allí dice: "No me acuerdo, cómo podría acordarme de ese diálogo. Pero fue así, lo escribo escuchándolo, o lo invento copiándolo, o lo copio inventándolo. Preguntarse de paso si no será eso la literatura" (158). Cortázar desecha la opción del pudor, su condición de escritor le permite realizar estos cruces sin problema, no se debe ni a la realidad, ni a la ficción, las interviene constantemente.

En los albores del desarrollo del género, Tolstoi, concebía la escritura diarística como un ejercicio de verdad cuyo fin era el perfeccionamiento de sí mismo: un examen de las acciones reprochables, que buscaba dejar atrás. Se puede verificar entonces que el malestar consigo mismo y cierto deseo de reparación se encuentran desde los inicios como una de las condiciones necesarias para el desarrollo de la escritura autobiográfica diarística, lo que Trapiello describe como "El escritor de diarios parte de un descontento, una desdicha o una insatisfacción, por lo que no cabe hablar de una relación narcisista, sino de una relación atormentada o anómala consigo mismo y con los demás” (26). Esta insatisfacción es resuelta por los escritores contemporáneos de forma diferente, abandonando la fidelidad con la verdad. La escritura (auto)biográfica, en estos casos, equivale a una invención del sujeto (y no tan sólo una representación de éste), en concordancia a lo propuesto por la crítica Lorena Amaro en Vida y escritura, se consolida de esta forma la entrega a la corriente textualista de la escritura autobiográfica, con la asunción del sujeto como producto de la escritura (26), lo que se opone a la concepción acérrima de este tipo de relatos como documento.

La propia vida es una narración que los sujetos se hacen de los sucesos vividos, esta se incorpora a la mente, sustituyendo lo realmente acontecido. Arfuch (2002) precisa que la narración es la que impone su forma y su sentido a la vida misma (28). Así la disposición del relato sustituye a la "verdad de la vida", lo 
CATEDRAL TOMADA: Revista de crítica literaria latinoamericana / Journal of Latin American Literary Criticism Las tensiones del yo escritor: el diario c omo lugar de experimentación en José Donoso y Ágata Gligo.

que se replica en la escritura diarística, que salva del olvido ciertos acontecimientos ordenándolos día a día, creando un registro más o menos inmediato de lo acontecido. Esta visión textualista triunfa finalmente sobre el referencialismo en los relatos autobiográficos. No es entonces la realidad, lo que se va a pesquisar en los diarios, sino que interesa la forma en que dicha realidad se ordena por parte de los autores.

\section{Los diarios de Donoso y Gligo}

En el caso de José Donoso, a través de Correr el tupido velo, conocemos de su obsesión por la figura del clochard, la que proyecta sobre su hija adoptiva. El escritor quiere que Pilar acoja la idea de no pertenencia de forma positiva y que esto le permita poder construirse desde cero, le propone "podrás trazar tú misma los rasgos de tu propio rostro" (440). Esta invitación corresponde al deseo del propio autor de construirse a sí mismo, al sentirse marginado por el resto, que según él lo mira con desconfianza, lo que plasma en una de las entradas del diario, de la siguiente forma: "La gente no me quiere porque soy sucio [...] siento que en una forma muy profunda y abarcadora, me identifico con la suciedad asquerosa de las viejas del Pájaro [El obsceno pájaro de la noche], y por eso no toco, no me dejo tocar..." (39). Este sentimiento de exclusión que atribuye a la sospecha sobre su homosexualidad, genera en Donoso la entrega a la construcción interminable de máscaras, lo que transforma en poética de su obra y no abandona ni siquiera en sus diarios.

Esto no se contradice con la voluntad por entregar una imagen total de sí mismo, develando en la escritura aquello que en la vida real, luchaba por ocultar: su sexualidad y dinámica familiar. Se evidencia una voluntad de la figura pública por entregar una imagen más completa; tanto de su obra, como de su vida íntima 'oculta', noción con la que juega el título de la obra, que pretende correr el tupido 
velo de la vida del escritor chileno. El mismo Donoso, dice: "Esta historia no invalida la imagen anterior, sino que la completa, le da una nueva mirada" (18); de esta forma el diario se configura como un medio para desenmascararse, sin embargo, este es un proceso sin fin ya que debajo de una máscara siempre hay otra, en sus palabras este "Es el diario de vida que cuenta el reverso de todo lo que el mundo sabe sobre él, pero sin jamás nombrar el pecado" (17).

Este pecado: su homosexualidad, se nombra de vez en cuando, sin embargo, las entradas de Donoso hacen dudar respecto a la veracidad de lo contado, ya que él mismo juega con la ambigüedad poniendo en duda muchas veces si lo narrado sucedió realmente. En las páginas finales de Correr el tupido velo se cita un fragmento extenso de un cuaderno de Donoso, donde escribe: "Prefiero no ser autentico y ser un escritor. Prefiero que esas zonas de mi ser, que son las más obscuras, queden incompletamente exploradas a condición de que pueda salvar algo de coherencia, algo de no disolución para tener energía y poder seguir escribiendo" (447). Hay algo de sí que se renuncia a entregar, algo que quiere mantener de forma privada. Nunca se accede al rostro real de Donoso debajo de todas esas máscaras. El velo se corre y descorre a su antojo.

La realización de esta impostura, que en la vida real se presenta como un mecanismo de sobrevivencia, en el texto sirve para completar la imagen del escritor: 'Las distintas máscaras son una herramienta, las usas porque te sirven para vivir. No sé qué es eso de la autenticidad. Lo que sé es que la vida es un complejo sistema de enmascaramientos y simulaciones" (Donoso 37-38). Si conocemos de sus paranoias, sus recriminaciones, sus temores e inseguridades sobre sí mismo y su obra, es porque él las ha novelado en el diario, configurándose como un personaje complejo. No hay que olvidar que el mismo Donoso es quien deja sus diarios a disposición, con el deseo de que alguien escribiera con estos su biografía, es decir, quiere posicionarse como una personalidad interesante. Además hay en ellos un reconocimiento de su posible escandalosa recepción, de lo cual le preocupa básicamente los efectos que pudiera tener sobre su hija. Es así como el autor consciente de la lectura de sus diarios, 
CATEDRAL TOMADA: Revista de crítica literaria latinoamericana / Journal of Latin American Literary Criticism Las tensiones del yo escritor: el diario c omo lugar de experimentación en José Donoso y Ágata Gligo.

juega con la morbosidad detrás de lo que escribe y es sumamente prolifico e incansable en la escritura de estos papeles.

Por su parte, el texto de Ágata Gligo Diario de una pasajera comienza registrando una conversación con Donoso, en la que él mismo le aconseja llevar un diario, recalcándole "que sea un diario de escritor, no de vida" (Gligo 15). ¿Qué quiere decir el novelista con esto? Que el diario de Gligo no se reduzca solo a lo intimista, sino que se constituya como un espacio de reflexión crítica, que le permita a la autora superar la sequía literaria que la aqueja. La escritora lo resuelve finalmente amalgamando ambos niveles, dando cuenta de su enfermedad, y los efectos que esta produce sobre el cuerpo femenino, así como su relación con el campo cultural chileno de los años 90. A la vez que logra sobreponerse a su incapacidad por terminar la novela que está escribiendo, reemplazándola finalmente por la escritura del diario, el cual corrige y comenta con otros autores. La narración de la vida cotidiana de la mujer se intercala con la inclusión de microrrelatos de los sueños de la autora, en los que se advierte una fuerte influencia bombaliana y del psicoanálisis, presente también en la figura de su analista que nombra como el "Gigante".

Uno de los motivos que prevalece a lo largo de este diario es la continua racionalización de todo aquello que se vive, lo que contrasta con el tono vehemente de los escritos de Donoso. Gligo busca una explicación a todo lo acontecido, a los sueños, a la sensación de descredito que siente frente a sus pares; además de buscar la causa de su propia enfermedad, posicionándose continuamente ella misma en el lugar del analista. Lugar que abandona solo en la narración de sus sueños, en los que se entrega por completo al oficio de contar. Con esto aumenta la sospecha en el lector, las entradas del diario, corregidas y pensadas para su publicación develan un plan escritural que se inclina por la búsqueda de explicaciones, no arrojándose nunca impetuosamente al devenir del diario, en el que "falta de apreciación de lo contingente e insignificante" (Giordano 62). La autora, como ella misma comenta, busca mediante la corrección y edición del texto darle un acabado literario y una unidad temática, 
presentando los hechos y su posible causa, ligando así la realidad, que es siempre caótica.

Gligo extrema el tratamiento literario del diario, sustentado en la "creencia en que el relato personal no es literario si no cumple una transfiguración de las experiencias reales" (Giordano, 62) y en la creencia de que la ficción constituye un peldaño superior, al que ella desea pertenecer. La autora idealiza la figura del novelista, la que encuentra sus referentes en el mismo Donoso y Diamela Eltit, quienes a su vez se presentan como figuras especulares dentro del diario, con los que, no se establece una relación del todo simétrica. Ella misma se posiciona por debajo de sus contemporáneos, al considerar que no ha publicado tantas obras como Donoso y Eltit, por lo que con su renuncia a escribir una novela, queda aún más atrás que los demás autores de su generación. Esta incapacidad narrativa se equipara a la muerte, o desaparición de la escena cultural. La autora, finalmente, se vuelca únicamente en la escritura de este texto, por lo que, en palabras de Giordano: "el diario de Gligo se convierte en un substituto de la obra imposible" (59), en esto se sustenta su afán de corrección y ordenamiento de las entradas.

Ambos autores narran las problemáticas que atormentan sus vidas y su obra, Donoso se arroja en un tono más confesional, que da cuenta de su capacidad narrativa, creando un sujeto contradictorio compuesto de máscaras, logrando mantener la duda sobre los límites de la realidad. Mientras que Gligo, lleva a cabo este proceso escritural, introduciendo secuencias narrativas de sueños y conversaciones con su psicoanalista, buscando conexiones entre estos y su vida, que tienden a cerrar los sentidos del relato.

\section{¿Por qué escribir un diario?}

El refugio de la intimidad del diario y su pertenencia al género autobiográfico, que supone una ilusión de verdad, sirven como condiciones 
CATEDRAL Tomada: Revista de crítica literaria latinoamericana / Journal of Latin American Literary Criticism Las tensiones del yo escritor: el diario c omo lugar de experimentación en José Donoso y Ágata Gligo.

suficientes mediante las cuales el Yo puede empoderarse de su propia imagen pública y construirla como desea que sea apreciada; dibujando, de esta forma, su propia máscara, es decir, realizando una autofiguración. Gesto que responde al descontento e inseguridad que siente el sujeto respecto a su propio Yo, comparandose continuamente con los demás escritores en cuanto a su obra y a su personalidad. Detrás de estos diarios hay un deseo de equipararse a sus contemporáneos, los que son nombrados, no de forma inocente, sino en busca de una afirmación de pertenencia al grupo, a la vez que se hace una defensa de la propia obra presentándola como un entramado complejo, resultado de una ardua reflexión.

Mediante la escritura del diario, Donoso y Gligo logran en parte llenar un vacío, tranquilizar su desasosiego, superar una enfermedad o enfrentar una verdad sexual, cristalizando un Yo interno al relato, mediante la tensión constante entre ficción y realidad. Así en este construirse literariamente, no se cuenta todo, renegando precisamente de lo que supondría la escritura de un diario. Se selecciona lo narrado y lo que se deja de contar, que adquiere también una carga semántica. El escritor de diarios no pretende dar cuenta a cabalidad todo lo acontecido en su vida, sino que necesita llevar un registro de sus ideas y experiencias como posible material novelable a posteriori, entendiendo estos textos como un lugar distinto al de sus obras narrativas. El diario es entonces el lugar de la experimentación, un lugar intermedio entre la ficción y la autobiografía, un espacio metatextual y de cristalización de su imagen pública, mediante el acceso controlado a la intimidad. 
CATEDRAL TOMADA: Revista literaria latinoamericana / Journal of Latin American Literary Criticism Daniela Alejandra Fernández Arriagada

\section{Bibliografía}

Amaro, Lorena. Vida y escritura: Teoría y práctica de la autobiografía. Santiago: Pontificia Universidad Católica de Chile, 2009.

Amícola, José. Autobiografía como autofiguración. La Plata: Beatriz Viterbo Editora, 2007.

Arfuch, Leonor. El espacio biográfico. Dilemas de la subjetividad contemporánea. Buenos Aires: Fondo de cultura económica, 2002.

Bradu, Fabienne. «Los pimientos verdes de Obama.» Revista de la Universidad de México (2009): 71-76.

Cortázar, Julio. «Diario de un cuento.»Deshoras. Alfaguara, 1983.

Donoso, Pilar. Correr el tupido velo. Santiago: Punto de lectura, 2013.

Giordano, Alberto. «En tránsito a ningún lugar. Sobre Diario de una pasajera de Ágata Gligo.» Iberoamericana (2009): 57-63.

Gligo, Ágata. Diario de una pasajera. Santiago: Alfaguara, 1997.

Lejeune, Philippe. «El pacto autobiográfico.» Suplementos Anthropos (1991): 4761.

Manzoni, Celina. «Biografía de artista y contemporaneidad en Roberto Bolaño.» Violencia y silencio: literatura latinoamericana contemporánea. Buenos Aires: Corregidor , 2005. 23-44.

Trapiello, Andrés. El escritor de diarios: Historia de un desplazamiento. Barcelona: Península, 1998. 